THE most appropiate management for bronchial asthma is the control of airway inflammation. Corticosteroids are the most effective anti-inflammatory drugs available, but they have a number of side effects; most of these are dose-dependent. In children, asthma control should be accomplished with low steroid doses possibly given by inhalation. In a double-bind placebo-controlled crossover study a group of children with mild to moderate asthma received NED $16 \mathrm{mg} /$ day or BDP $400 \mu \mathrm{g} /$ day. Values for $\mathrm{FEV}_{1}$, PEF, symptoms use of bronchodilators overlapped, whereas bronchial hyper-responsiveness assessed by histamine bronchoprovocation challenge was better with BDP than NED. In another case, one boy with high bronchial hyper-reactivity assessed by provocation test with hypertonic solution, experienced a significant improvement only after 2 weeks of therapy with Deflazacort ( $2 \mathrm{mg} / \mathrm{Kg} / \mathrm{day}$ ) followed by 4 months on combined treatment with NED (16 mg/day) and BDP (300 $\mu \mathrm{g} /$ day). Authors conclude that NED could have a steroidsparing effect over long-term use.

\section{Corticosteroid-sparing effect of chromoglycate sodium and nedocromil}

\author{
A. F. Capristo, M. Miraglia del Giudice Jr, ${ }^{\mathrm{CA}}$ \\ C. Alfaro and N. Maiello
}

Paediatric Clinic, University of Naples, via Sant'Andrea delle Dame, 4-1-80100 Naples, Italy

CA Corresponding Author
It is now clear that the most appropriate management of bronchial asthma is to control airway inflammation. ${ }^{1,2}$ The drugs able to reduce inflammation in asthmatic children are in the following order of decreasing activity: systemic steroids; inhaled steroids (IS); nedrocromil sodium (NED); sodium cromoglycate (SGC); and probably ketotifen. . $^{3-5}$

The anti-inflammatory role of the new long-acting beta-2 agonist, salmeterol, has not been established because a 12-week treatment period of doses effective in controlling symptoms did not show any significant effect on mast cells, eosinophils, T-cells or the epithelium of bronchial mucosa and submucosa. ${ }^{6}$

\section{Anti-inflammatory drugs and mild-to- moderate asthma}

The international guidelines about asthma management suggest regular anti-inflammatory therapy should be given in mild persistent, moderate and severe asthma. Only mild episodic asthma should be treated exclusively with environmental control and beta-2 agonist on demand. However, it is not certain which anti-inflammatory agent should be used as first-line therapy..$^{7-9}$

Corticosteroids are the most effective anti-inflammatory drugs, ${ }^{9}$ but they have a number of side effects (Tables 1 and 2). Inhaled steroid therapy is effective in controlling asthma without the side effects associated with systemic administration, although recent reports have shown that the dose of $400 \mathrm{mcg} / \mathrm{day}$ is not 'safe', since growth may be affected, ${ }^{10}$ the
Table 1. Side effects of inhaled corticosteroids

Local side effects

- Cough

- Bronchostenosis

- Oral candidosis

- Atrophic glossitis

- Haemorrhagic angina

- Dysphonia

- Chronic oesophagitis

- Laryngeal candidosis

Table 2. Side effects of inhaled corticosteroids

Systemic side effects

- HPA suppression

- Growth delay in asthmatic children

- Interference in bone formation

- Reduction of circulating eosinophils and lymphocytes

- Metabolic effects

- Cataract

- Cushing syndrome faeces

- Derma thinning

- Purpura

hypophysio-pituitary-adrenal axis may be suppressed $^{11,12}$ and bone metabolism may be influenced. ${ }^{13}$

Sodium cromoglycate (SCG) may be the drug of choice in children with mild-to-moderate asthma, because of its optimal ratio between effectiveness and safety. ${ }^{14}$ SCG is able to control both clinical symptoms and bronchial hyper-responsiveness; it is also active in reducing the number of inflammatory cells in the asthmatic airway. ${ }^{15-18}$ SGC is equally effective as low doses of inhaled steroids, but has the advantage of being safer. ${ }^{19-21}$ 
Table 3. Clinical features of children recruited for the trial in treatment group $1^{*}$

\begin{tabular}{ll}
\hline Age, mean (range) & $10.46(8-13$ years) \\
Sex & $7 \mathrm{~F}$ and $8 \mathrm{M}$ \\
FEV1 \%, mean (range) & $73.39(70.2-79.1)$ \\
$\%$ Reversibility & $19.76(16.7-22.5)$ \\
after Beta-2, mean (range) & \\
PC20 Histamine, mean (range) & $670(250-1200)$ \\
Allergic asthma & $15 / 15$ (Dermat. +++)
\end{tabular}

*Trial started with BDP $400 \mathrm{mcg} / \mathrm{day}+$ placebo for 6 weeks, then cross-over with nedocromil sodium $16 \mathrm{mg}$ (NED) + placebo.
Table 4. Clinical features of children recruited for the trial in treatment group $2^{*}$

\begin{tabular}{ll}
\hline Age, mean (range) & 10.6 (8-13 years) \\
Sex & $5 \mathrm{~F}$ and $10 \mathrm{M}$ \\
FEV1 \% mean (range) & $70.02(69.3-78.5)$ \\
$\%$ Reversibility & $19.56(16.7-22.7)$ \\
after Beta-2, mean (range) & \\
PC20 Histamine, mean (range) & $653(400-1000)$ \\
Allergic asthma & $13 / 15$ (Dermat. +++)
\end{tabular}

*Trial started with NED $16 \mathrm{mg} / \mathrm{day}+$ placebo for 6 weeks, then cross-over with BDP $400 \mathrm{mcg} /$ day + placebo.

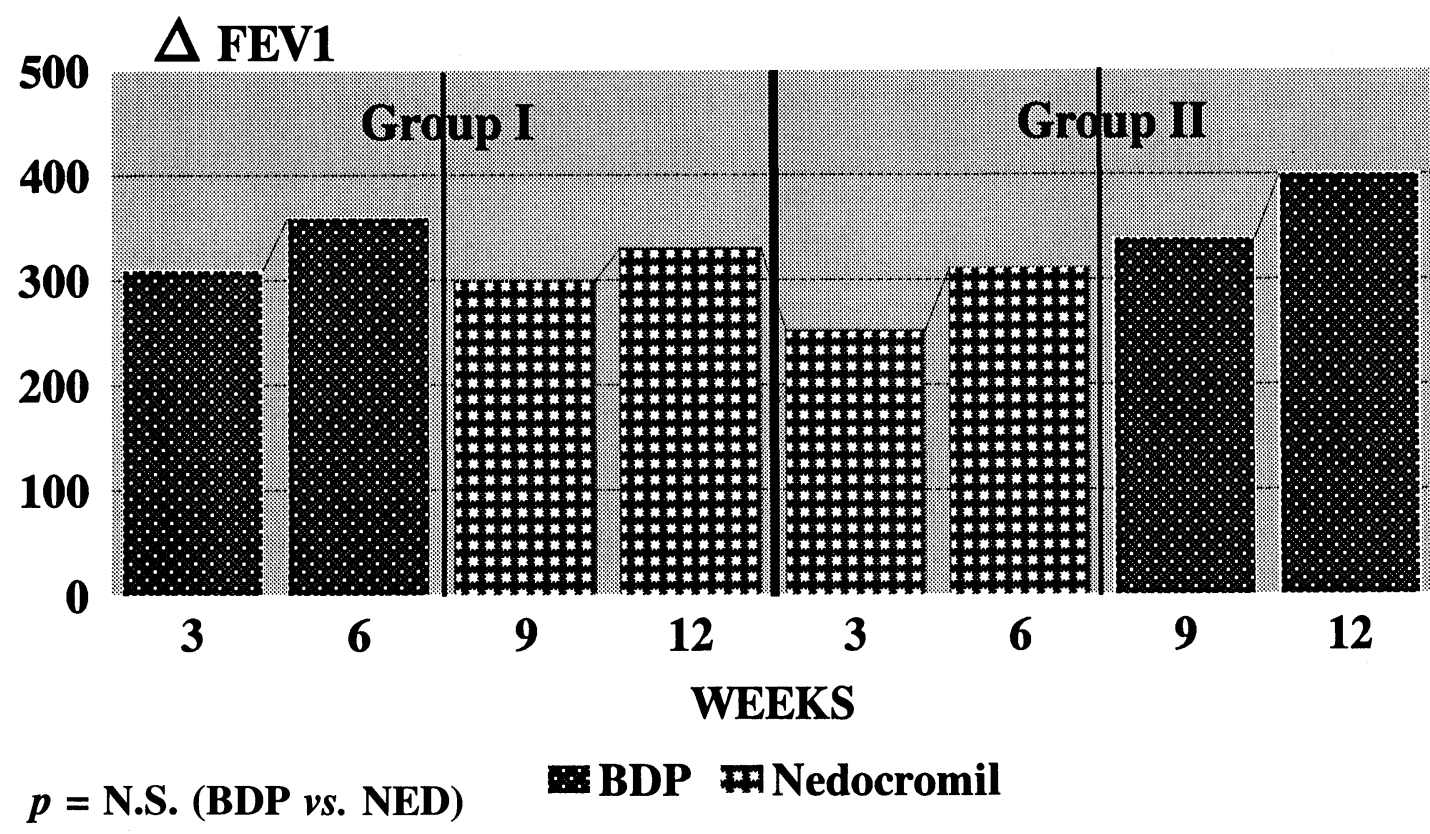

FIG. 1. BDP vs. nedocromil. $\triangle$ FEV1 (mean change from baseline) in the I and II groups treated.

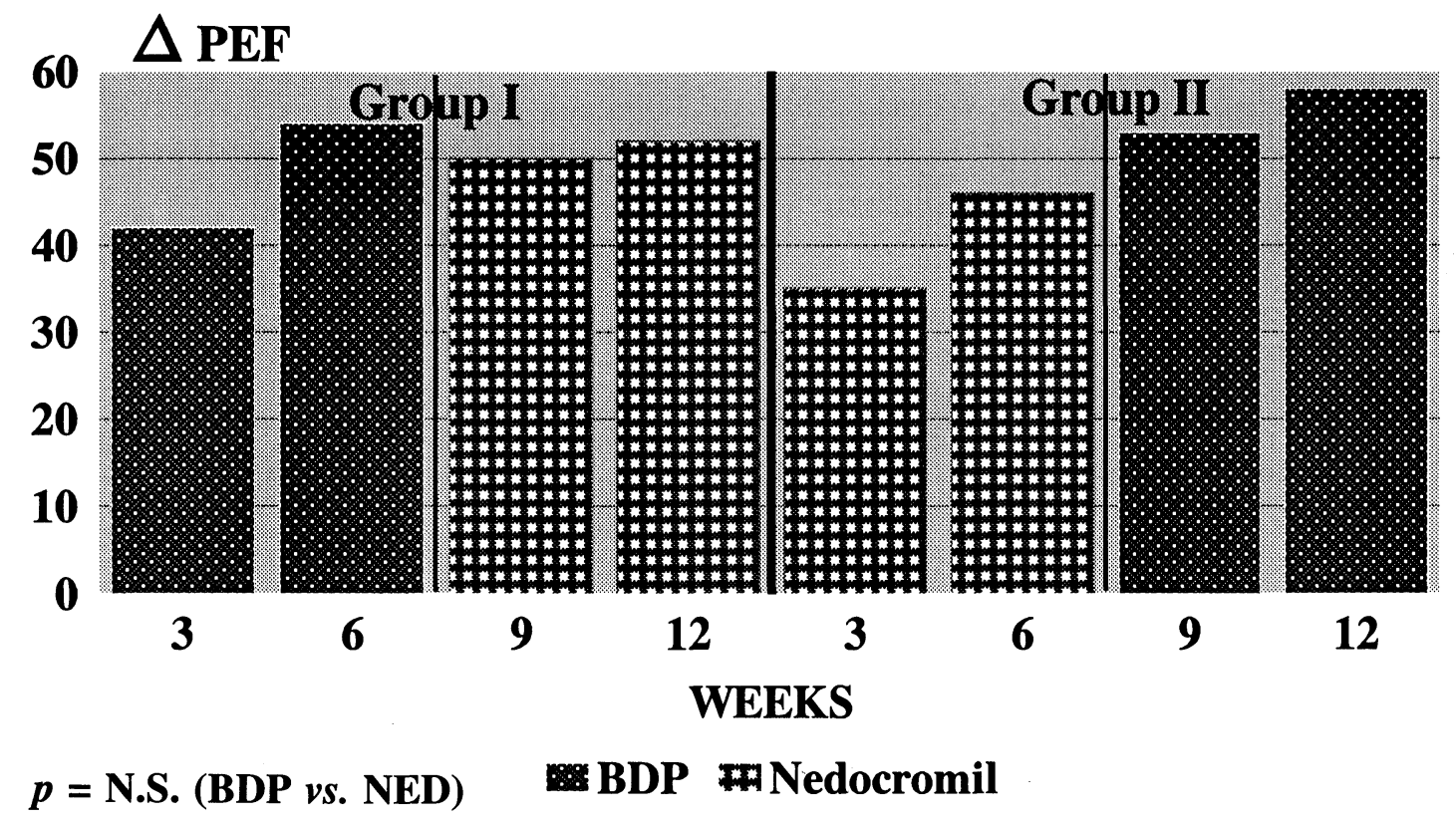

FIG. 2. BDP vs. nedocromil. $\Delta$ PEF (mean change from baseline) in the I and II groups treated. 


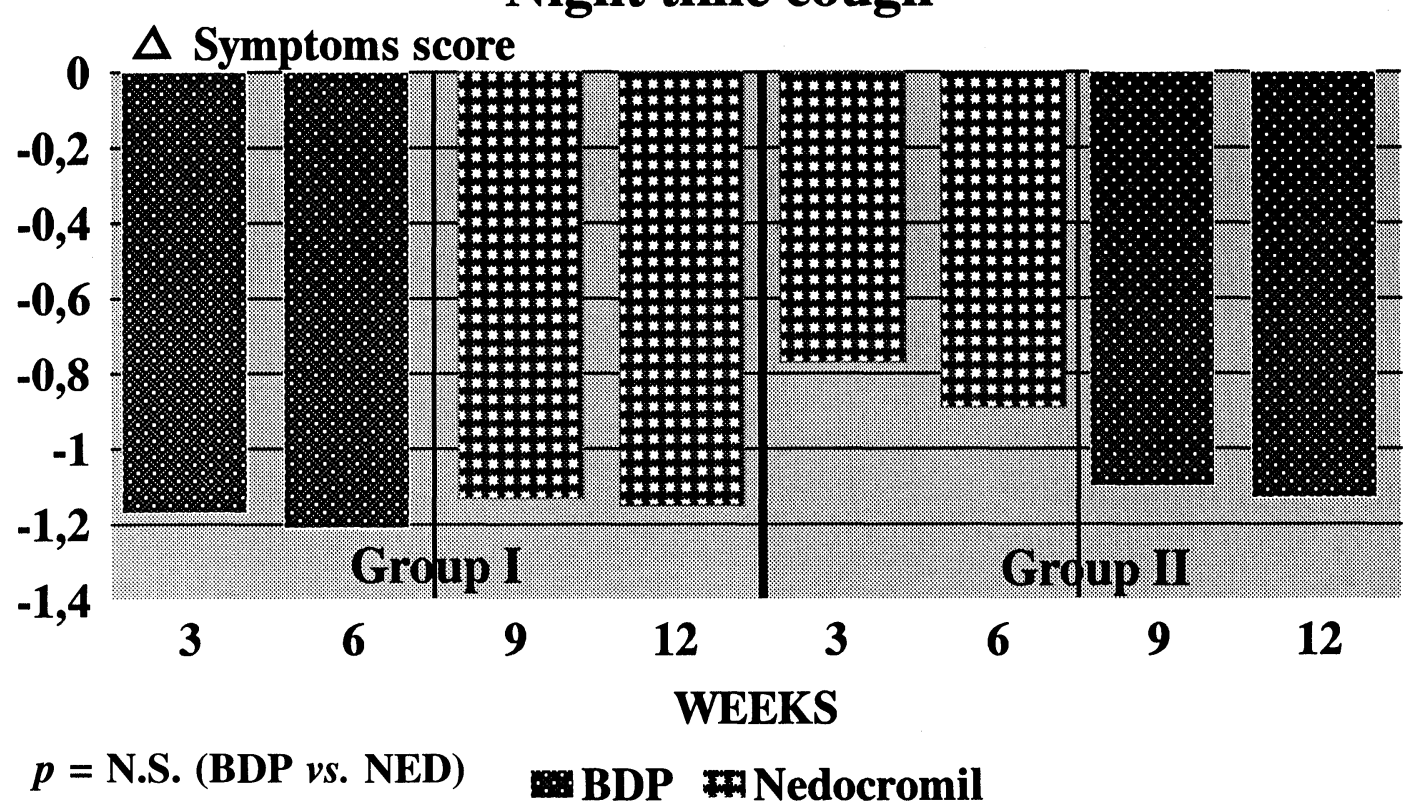

FIG. 3. BDP vs. nedocromil. $\Delta$ Symptoms score (mean change from baseline) in the I and II groups treated.

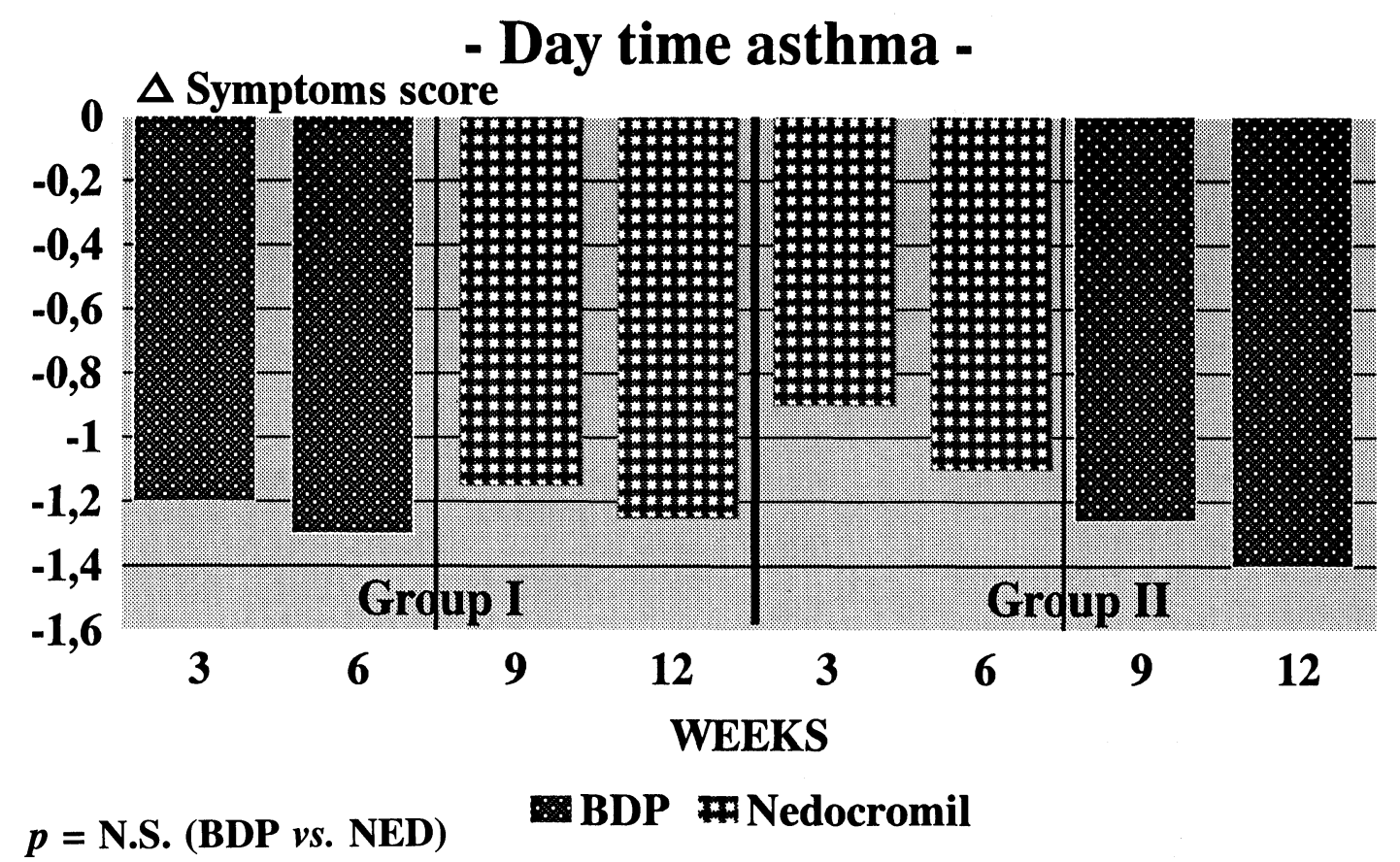

FIG. 4. BDP vs. nedocromil. $\Delta$ Symptoms score (mean change from baseline) in the I and II groups treated.

Table 5. Nedocromil sodium and steroids: reduction of corticosteroids therapy in adult asthmatic patients

\begin{tabular}{lccc}
\hline $\begin{array}{l}\text { Authors } \\
\text { (ref) }\end{array}$ & $\begin{array}{c}\text { Treatment duration } \\
\text { (weeks) }\end{array}$ & $\begin{array}{c}\text { Nedocromil } \\
\text { (dose, mg) }\end{array}$ & $\begin{array}{c}\text { Steroid-sparing } \\
\text { effect }\end{array}$ \\
\hline $\begin{array}{l}\text { Bone et al. (25) } \\
\text { Svendsen and }\end{array}$ & 4 & 16 & yes \\
Jorgensen (26) & 8 & 16 & no \\
Orefice et al. (27) & 12 & 16 & yes \\
Paananen et al. (28) & 12 & 16 & no \\
Ruffin et al. (29) & 4 & 16 & yes \\
Goldin and & 20 & 16 & no \\
Bateman (30) & & & yes \\
Wong et al. (31) & 16 & 16 & no \\
Boulet et al. (32) & 12 & 16 & \\
\hline
\end{tabular}

Nedocromil sodium (NED) has been shown to be equally or more effective than SCG as an anti-inflammatory agent, especially in intrinsic asthma. ${ }^{22-24}$ In this paper, we report the results of a double-blind cross-over study comparing the effects of NED (16 $\mathrm{mg} /$ day) and BDP (400 mcg/day) on symptoms and bronchial hyper-responsiveness in 30 children with moderate asthma (Tables 3 and 4, and Figs 1-6). The patients had a wash-out off-therapy period for a minimum of 2 months. After a 2-week run-in period, children were randomly allocated to two similar treatment groups (Tables 3 and 4), receiving BDP $(400 \mathrm{mcg} /$ day $)+$ placebo or NED $(16 \mathrm{mg} /$ day $)+$ 


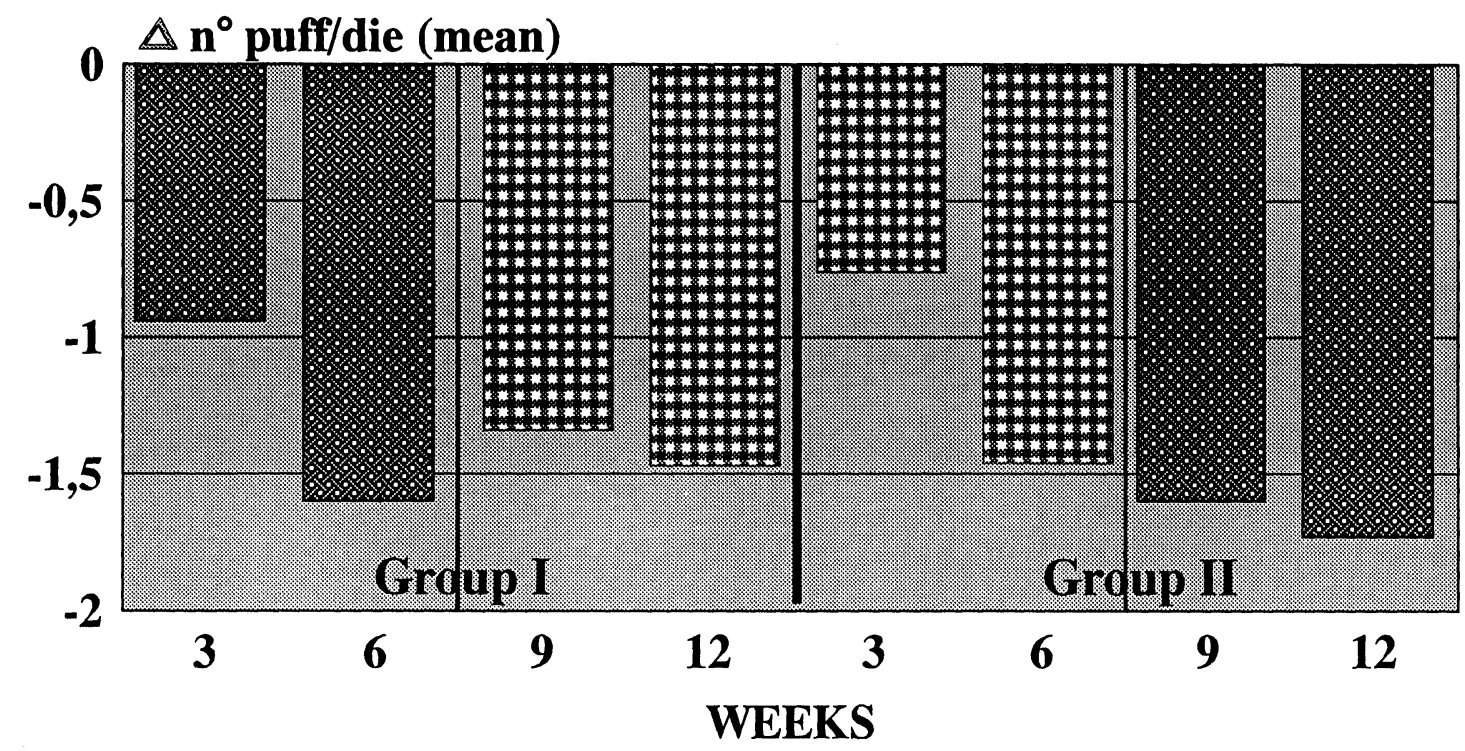

$p=$ N.S. (BDP vs. NED)

BDP Nedocromil

FIG. 5. BDP vs. nedocromil. $\Delta n^{\circ}$ puff/die of Beta2 (mean change from baseline) in the I and II groups treated.

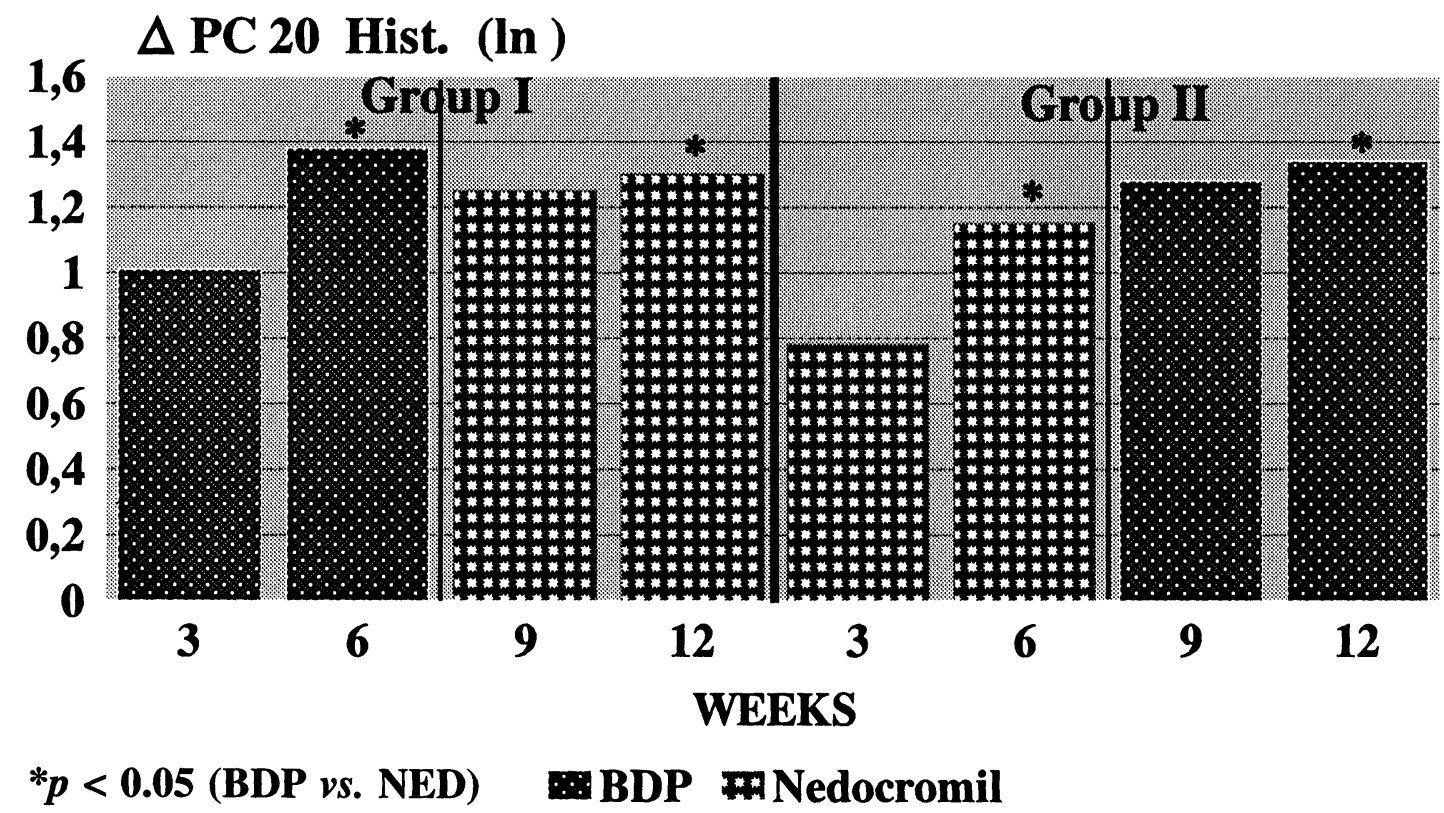

FIG. 6. BDP vs. nedocromil. $\triangle$ PC 20 Histamine (mean change from baseline) in the I and II groups treated.

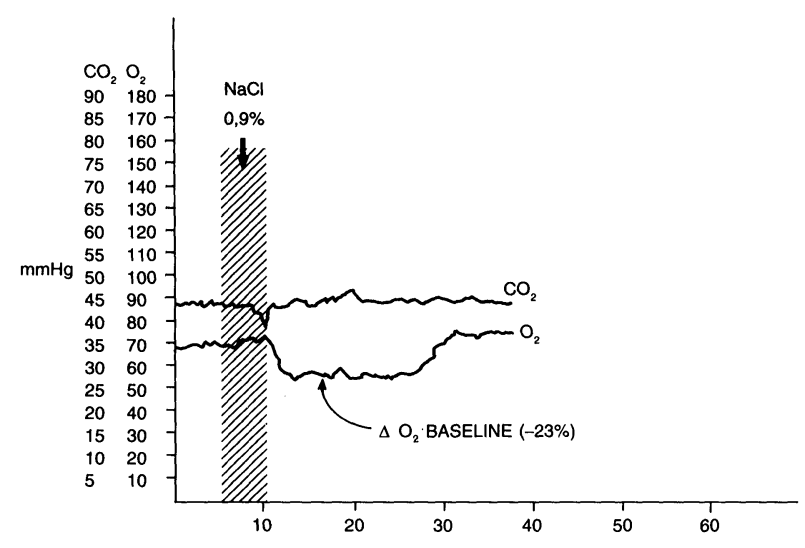

FIG. 7. Hyperosmolar solution challenge at baseline.

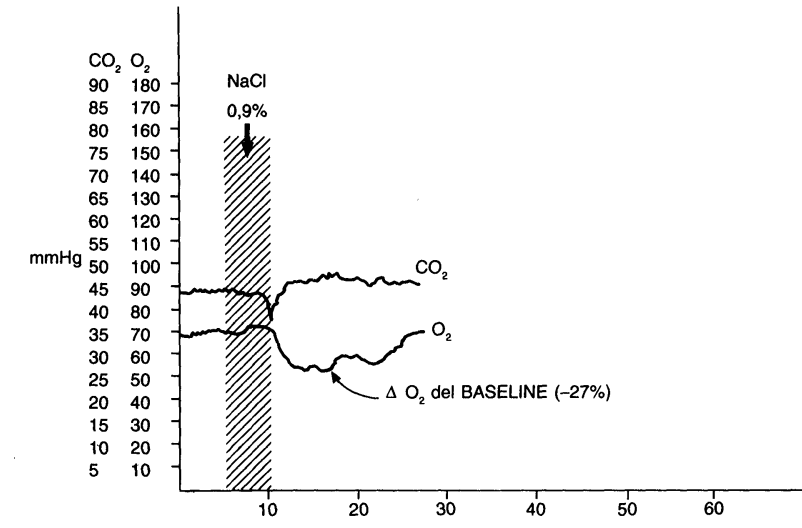

FIG. 8. Hyperosmolar solution challenge after 2 months' therapy with NED. 


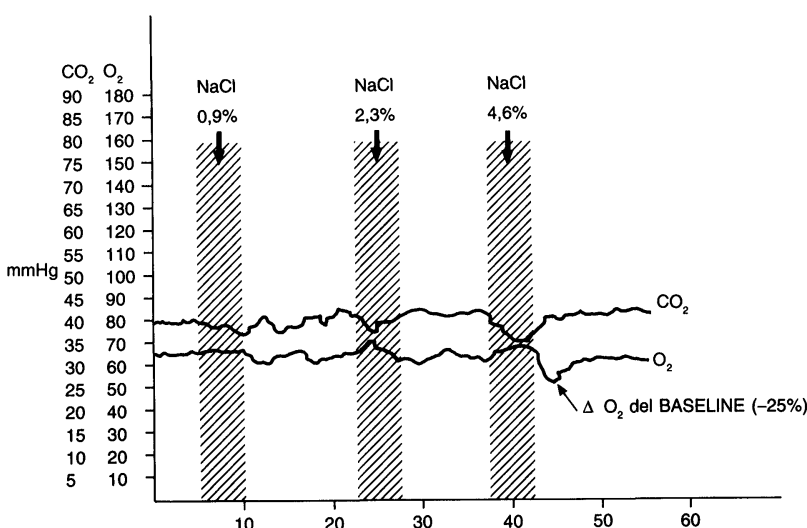

FIG. 9. Hyperosmolar solution challenge after 2 weeks' therapy with Deflazacort.

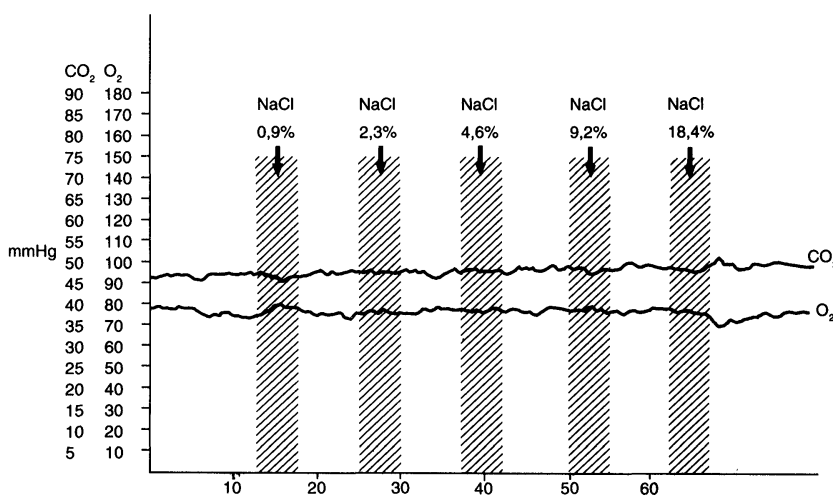

FIG. 10. Hyperosmolar solution challenge after 4 months' theapy with NED + BDP.

placebo, respectively, for 6 weeks in a cross-over design. Assessment was made by diary cards, bronchodilator use and intermittent clinical evaluation, spirometry and histamine bronchoprovocation challenge (at baseline and after 3, 6, 9 and 12 weeks). No significant difference ( $t$-test analysis) was found between the two treatment groups (Figs 1-5), except that the PC20 histamine was significantly higher after 6 weeks in the corticosteroid group $(p>$ 0.05) (Fig. 6).

Our study also showed that NED is not effective before 4 weeks of treatment. Furthermore, in an unpublished follow-up study, we found that the highest values of FEV1 occurred after 3 months of continuous treatment with NED.

In moderate to severe asthma, anti-inflammatory therapy with SCG or NED should be reinforced by increasing doses (i.e. SCG $40 \mathrm{mg} \times 4$ times/day) and/ or by increasing the times of administration ${ }^{23}$ and/or by adding inhaled steroids. Dose adjustments of inhaled steroids should be made on the basis of clinical response, but high doses are not usually required because of the steroid sparing effect of SCG and NED.
It has been demonstrated that NED (16 mg/day) could replace BDP $(330 \mathrm{mcg} /$ day $){ }^{25}$ When overall control of asthma is achieved, inhaled steroids should be gradually reduced until the lowest effective dose is found or until their gradual but complete withdrawal.

Figures 7-10 show the results of provocation tests with hypertonic solution by monitoring $\mathrm{po}_{2}$ and $\mathrm{pCO}_{2}$ with Gasthmatic, in an 8-year-old boy with moderate allergic asthma. The hyperosmolar solution challenge was performed with increasing concentrations of $\mathrm{NaCl}$ solution (2.3-4.6-9.2-18.4\%) administered by ultrasonic nebuliser. At baseline, the patient already expressed significant derangements in $\mathrm{PO}_{2}$ and $\mathrm{PCO}_{2}$ on inhalation of normosmolar solution (Fig. 7). Two months after NED (16 mg/day), the findings were unchanged (Fig. 8). Fourteen days on Deflazacort ( $2 \mathrm{mg} / \mathrm{Kg} /$ day) brought about a reduction in bronchial inflammation (Fig. 9). The challenge became negative after four months of treatment with NED (16 mg/day)+BDP (300 mg/day) (Fig.10).

\section{Anti-inflammatory Drugs and Severe Asthma}

In severe asthma, which is fortunately rare in childhood, corticosteroids are widely accepted as a first-line therapy. ${ }^{9}$ When control of asthma appears to require continuous treatment with steroids, an alternative diagnosis should be first suspected, since a number of non-asthmatic conditions may cause wheezing or dyspnea (i.e. cystic fibrosis, congenital heart disease, recurrent aspiration).

When the diagnosis of asthma is certain, all the precipitating trigger factors (such as food allergens, cigarette smoke, occupational and environmental exposure, chronic sinusitis) should be identified and removed where possible. Before starting with steroid therapy, it is also necessary to control the adequacy of the previous therapeutic regimen, ensure the patient's compliance, and to control the inhalation technique and the aerosol delivery system output.

In cases requiring the use of steroids, inhaled steroids are the first choice treatment. ${ }^{9}$ However, the therapeutic effects of inhaled steroids are dose-dependent, high-dose inhaled steroid therapy shows an increased risk of side effects, including adrenal and growth suppression..$^{11,12}$

The minority of asthmatic children continuing to have an inadequate response to inhaled steroids need to go on to have oral administration. Oral steroids should be used at the lowest effective dose possible and be given on alternate days. ${ }^{9}$ The ability of SCG and NED in reducing steroid requirements in steroid-dependent asthmatic patients is controversial, as shown in Table $5 .{ }^{25-33}$ Dissimilar results in different trials could depend on the early suspension of ster- 
inhaled steroids after their withdrawal, which lasts for about 3 months. ${ }^{34}$ In asthmatic children who are dependent on oral steroids, drugs such as troleandomicin, ${ }^{35}$ methotrexate, ${ }^{36}$ cyclosporin, ${ }^{37}$ and high dose i.v. immunoglobulins, ${ }^{38}$ could be useful for their steroid-sparing effect. However, as there is not enough good and safe evidence in support of these drugs in childhood asthma, their use cannot yet be recommended.

\section{Conclusions}

In most cases, bronchial asthma requires antiinflammatory treatment which should be started as early as possible. Laitinen et al. ${ }^{7}$ demonstrated a significant increase in eosinophils $(p<0.001)$, lymphocytes $(p<0.001)$ and plasma cells $(p<0.001)$ in bronchial mucosa, even in the mildest of asthmatic patients with a diagnosis made between 2 and 12 months ago. Since asthma is a chronic disease, antiinflammatory therapy could be used for many years. Thus, SCG and NED should be considered as a firstline therapy because of their optimal safety profile. Corticosteroids should be reserved for patients whose symptoms are not completely controlled by courses of at least 2-3 months with SCG or NED used at dosages even higher than those conventionally suggested. Inhaled steroids, when they are required to control the disease, should be associated with SCG or NED in order to reduce the steroid dose.

\section{References}

1. Holgate ST. Asthma: past, present and future. Eur Respir J 1993; 6: 1507-1520.

2. National Heart, Lung and Blood Institute International Consensus Report on Diagnosis and Management of Asthma US Department of Health and Human Service, Publication No. 92-3091, June 1992.

3. Djukanovic R, Wilson JW, Britten KM, et al. Effect of an inhaled corticosteroid on airway inflammation and symptoms in asthma. Am Rev Respir Dis 1992; 145: 669-674.

4. Trigg C, Manolitsas N, McAuley A, et al. A pilot comparative study of the effects of inhaled nedocromil sodium and albuterol on bronchial biopsies in asthma. Am Rev Respir Dis 1993; 147: A522.

5. Diaz P, Galleguillos FR, Gonzales CM, et al. Bronchoalveolar lavage in asthma: the effect on sodium cromoglycate (cromolyn) on leucocyte counts, immunoglobulin and complement. J Allergy Clin Immunol 1984; 74: 41-48.

6. Roberts JA, Bradding P. The effect of salmeterol therapy on mucosal inflammation in asthma. Am Rev Respir Dis 1992; 145: A418 (abstract).

7. Laitinen LA, Laitinen A, Haahtela T. Airway mucosal inflammation even in patients with newly diagnosed asthma. Am Rev Respir Dis 1993; 147: 697-704.

8. Szefler SI. Potential adverse effects of topical steroids. Ann Meeting Am Coll Allergy Immunol Chicago Illinois, 15 November 1992; 117-125.

9. Doull IJM, Freezer NJ, Holgate ST. Growth of asthmatic children on inhaled corticosteroids. Am Rev Resp Dis 1993; 147: A265.

10. Padfiekd PL, Teelucksing S. Inhaled corticosteroids-the endocrinologist's view Eur Respir Rev 1993; 3: 449-500.

11. Phillip M, Aviram M, Leberman F, et al. Integrated plasma cortisol concentration in children with asthma receiving long term inhaled corticosteroids. Ped Pulmonol 1992; 12: 84-89.
12. Sorva $\mathrm{R}$, Turpeinem M, Juntunen-Backman $\mathrm{K}$, et al. Effects of inhaled budesonide on serum markers of bone metabolism in children with asthma. J Allergy Clin Immunol 1992; 90: 808-815.

13. Dukes MNG, Holgate ST, Pauwels RA. Report of an international workshop on risk and safety of asthma therapy. Clin Allergy 1994; 24: 1-6.

14. Watanabe $H$. The effect of disodium cromoglycate against bronchial hyperresponsiveness in asthmatic children. J Astbma 1992; 29: 117-120.

15. Shapiro GG, Furukawa CT, Pierson WE, et al. Double-blind evaluation of nebulized cromolyn, terbutaline and combination for childhood asthma. J Allergy Clin Immunol 1988; 81: 449-454.

16. Cockcroft DW, Murdock KV. Comparative effects of inhaled salbutamol, sodium cromoglycate and beclomethasone dipropionate on allergen - induced early asthmatic response, late asthmatic response and increased bronchial responsiveness histamine. J Allergy Clin Immunol 1987; 79: 734-738.

17. Shapiro GG, Sharpe M, De Rouen TA, et al. Cromolyn versus triamcinolone acetonide for youngest with moderate asthma. J Allergy Clin Immunol 1991; 88 742-748.

18. Kuzemko JA, Bedford S, Wilson $\mathrm{L}$, et al. A comparison of beclo-methasone valerate aerosol and sodium cromoglycate in children with reversible airways obstruction Postgrad Med J 1974; 50 (Suppl 4): 53-58.

19. Francis RS, McEnery G. Disodium cromoglycate compared with beclomethasone dipropionate in juvenile asthma. Clin Allergy 1984; 14: 537-540.

20. Mitchel I, Paterson IC, Cameron SJ, et al. Treatment of childhood asthma with sodium cromoglycate and beclomethasone dipropionate aerosol singly or in combination. Br Med J 1976; 2: 457-458.

21. Price JF. Corticosteroids and other anti-inflammatory agents in the treatment of children. Eur Respir Rev 1994; 4: 27-32.

22. Bel EH, Timmers MC, Hermans J, et al. The long-term effects of nedocromil sodium and beclomethasone dipropionate on bronchial responsiveness to methacoline in non atopic asthmatic subjects. Am Rev Respir Dis 1990; 141: 21-28.

23. de Jong JW, Postma DS, de Monchy JGR, et al. A review of nedocromil sodium in asthma therapy. Eur Respir Rev 1993; 3: 511-519.

24. Bergman K, Bauer $\mathrm{CP}$, Overlack A. A placebo controlled, blind comparison of nedocromil sodium and beclomethasone dipropionate in bronchial asthma. Cur Med Res Opin 1989; 11: 533-542.

25. Bone MF, Kubik MM, Keaney $\mathrm{P}$, et al. Nedocromil sodium in adults dependent on inhaled corticosteroids: a double blind, placebo controlled study. Thorax 1989; 44 654-659.

26. Svendsen UG, Jorgensen $\mathrm{H}$. Inhaled nedocromil sodium as additional treatment to high dose inhaled corticosteroids in the management of bronchial asthma. Eur Respir J 1991; 4: 992-999.

27. Orefice U, Struzzo P, Dorigo $\mathrm{P}$, et al. Long term treatment with sodium cromoglycate, nedocromil sodium and beclomethasone dipropionate reduces bronchial hyper-responsiveness in asthmatic subjects. Respiration 1992; 59: 97-101.

28. Paananen M, Karakorpi T, Kreus KE. Withdrawal of inhaled corticosteroid under cover of nedocromil sodium. Eur J Respir Dis 1986; 69 (Suppl 147): 330-335.

29. Ruffin R, Alpers JH, Kroemer DK, et al. A 4 week Australian multicentre study of nedocromil sodium on asthmatic patients. Eur J Respir Dis 1986; 69 (Suppl 147): 336-339.

30. Goldin JG, Bateman ED. Does nedocromil sodium have a steroid-sparing effect in adult asthmatic patients requiring maintenance oral corticosteroids? Thorax 1988; 43: 982-986.

31. Wong CS, Cooper S, Britton GR, et al. Steroid-sparing effect of nedocromil sodium in asthmatic patients taking high doses of inhaled steroids. Thorax 1991; 46 $768 \mathrm{p}-769 \mathrm{p}$

32. Boulet LP, Cartier A, Cockcroft DW, et al. Tolerance to reduction of oral steroid dosage in severely asthmatic patients receiving nedocromil sodium. Respir Med 1990; 84: 317-323.

33. Juniper EF, Kline PA, Vanzieleghem MA, et al. Reduction of budesonide after a year of increased use: a randomized controlled trial to evaluate whether improvements in airway responsiveness and clinical asthma are maintained. $J$ Allergy Clin Immunol 1991; 87: 483-489.

34. Toogood JH, Jennings B, Lefcoe NM. A clinical trial of combined cromolyn/ beclomethasone treatment for chronic asthma. J Allergy Clin Immunol 1981; 67: 317-324.

35. Wald JA, Friedman BF, Farr RS. An improved protocol for the use of troleandomycin (TAO) in the treatment of steroid-requiring asthma. J Allergy Clin Immunol 1986; 78: 36-43.

36. Shiner RJ, Nunn AJ, Chung KF, et al. Randomised, double-blind, placebo controlled trial of methotrexate in steroid-dependent asthma. Lancet 1990; 336: 137-140.

37. Szczeklik E, Nizankowska E, Dworski B, et al. Cyclosporin for steroid-dependent asthma. Allergy 1991; 46: 312-315.

38. Mazer BD, Gelfand EW. An open-label study of high-dose intravenous immunoglobulin in severe childhood asthma. J Allergy Clin Immunol 1991; 87: 976-983 


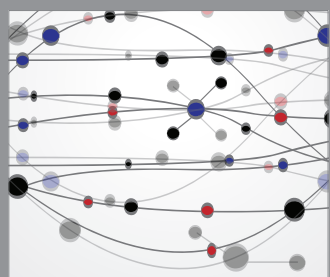

The Scientific World Journal
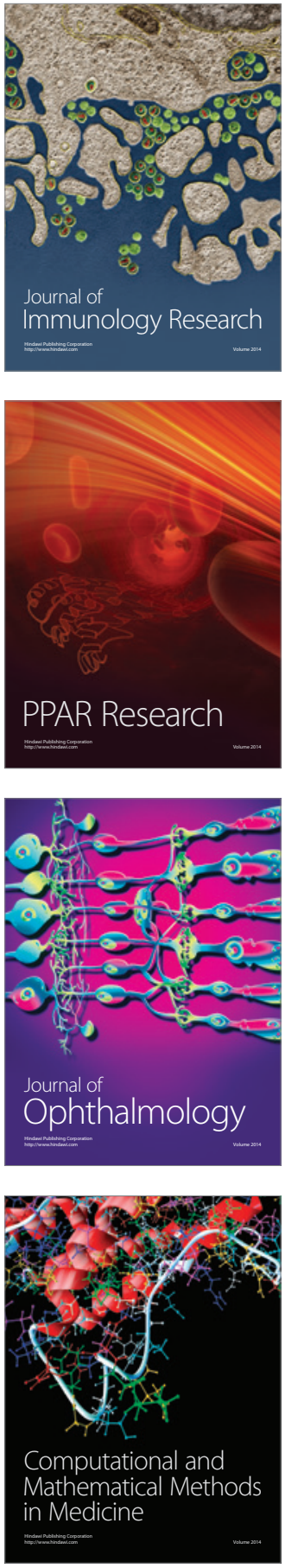

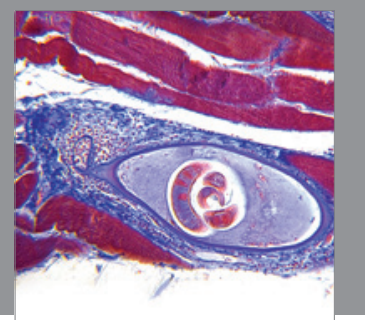

Gastroenterology

Research and Practice
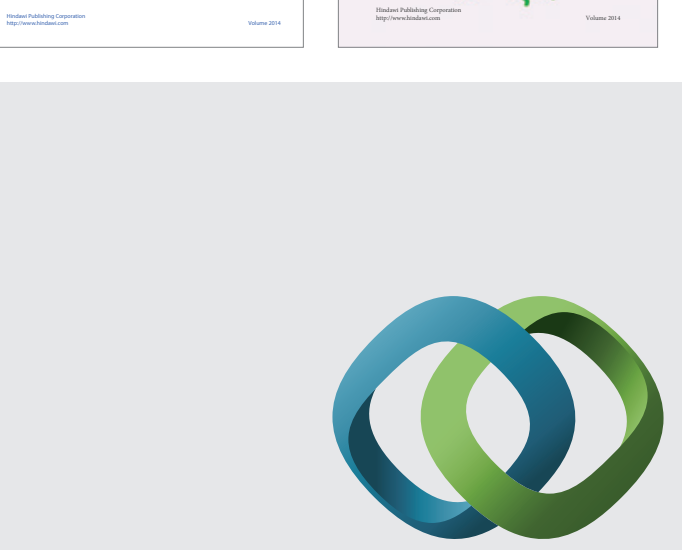

\section{Hindawi}

Submit your manuscripts at

http://www.hindawi.com
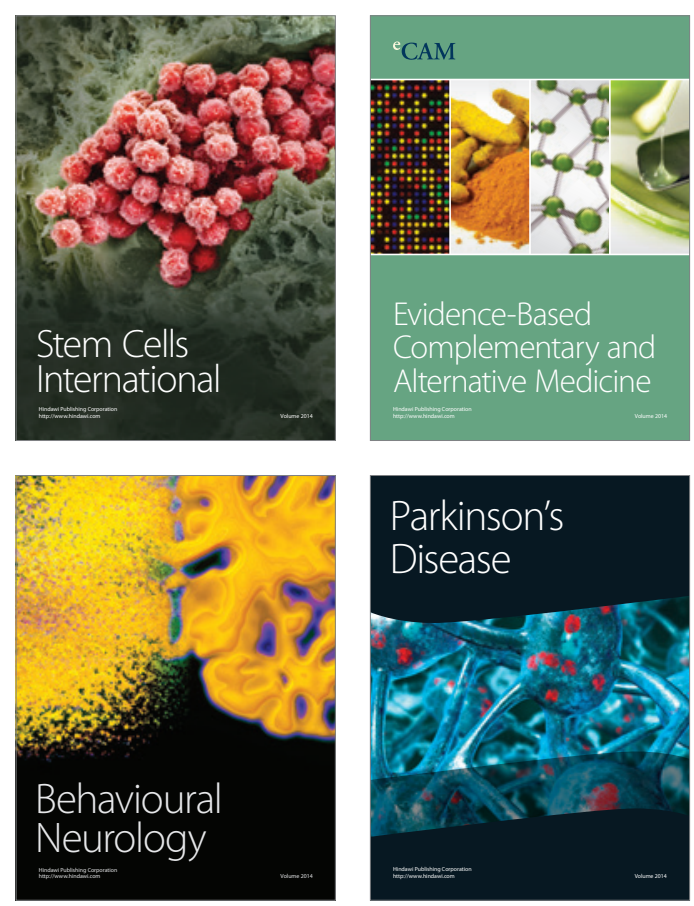

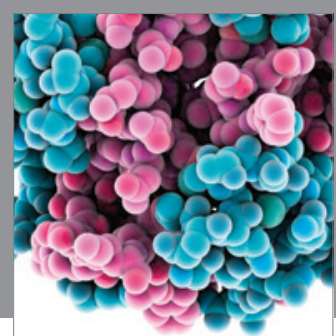

Journal of
Diabetes Research

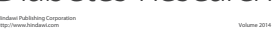

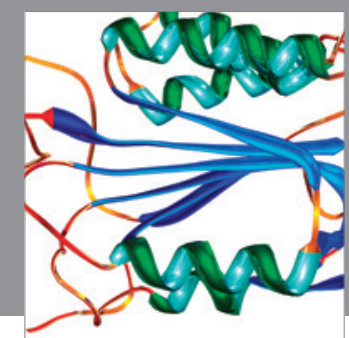

Disease Markers
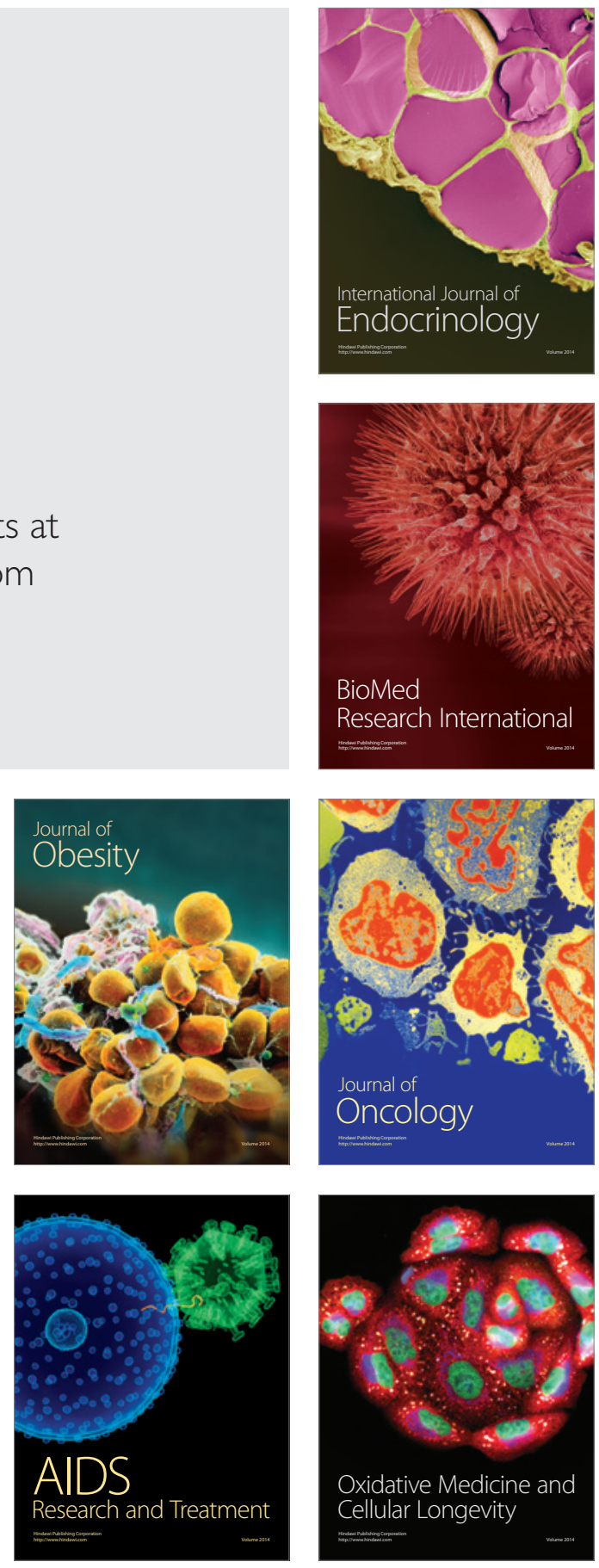